\title{
PRECONCEITO E MEMÓRIA: POR QUE NA ESCOLA ERA TÃO DIFÍCIL?
}

Adriana Maria Ribeiro Gil-Ferreira é doutoranda em Educação na PUC-Rio. Email: dantasamr@yahoo.com.br

\begin{abstract}
Resumo
Não se pode negar que a escola é sensível às manifestações de preconceitos que estão arraigados na sociedade e que são constitutivos de nossa memória. Com o objetivo de pô-los em questão, busco de início, com a ajuda de Gadamer e Kant, elucidar o que significa "preconceito". Em seguida, abordo o problema da desconstrução dos preconceitos no interior da escola, a partir da análise do diálogo e da relação de autoridade.
\end{abstract}

\begin{abstract}
It cannot be denied that the school is sensitive to the manifestations of prejudices that are rooted in society and that are constitutive of our memory. With the purpose of calling them into question, I try firstly to elucidate the meaning of "prejudice" with the help of Gadamer and Kant. I tackle thereafter the problem of the deconstruction of prejudices inside school, by means of an analysis of dialogue and of authority relationship.
\end{abstract}

\section{1) Introdução}

A pesquisa realizada por Nilma Lino Gomes (2003), que buscou resgatar na memória de adultos negros algumas lembranças trazidas dos tempos da escola, exemplifica bem a questão que desejo abordar nesse artigo. Durante a pesquisa, Gomes entrevistou algumas pessoas dentro de salões étnicos, que cuidam principalmente da beleza de pessoas negras, por compreender que estes eram também lugares de formação de identidades. Como resultado da fala dos entrevistados, a autora chegou à conclusão de que a escola é um lugar onde as manifestações dos preconceitos se dão de forma intensa, provocando marcas profundas na memória das pessoas. $\mathrm{O}$ presente artigo não tem como objetivo tratar do tema da identidade negra e nem voltar às questões da pesquisa mencionada. Contudo, acredito que a partir dessa pesquisa, somos levados a nos perguntar: como se formam tais preconceitos e por que eles não se desfazem a partir da nossa própria vontade? Por que na escola essa manifestação de preconceitos acontece de forma tão intensa? Por que essas identidades minoritárias, justo na infância, momento das primeiras descobertas, são tão violentamente atacadas? Como essas experiências constroem memória num amplo sentido do termo? Como podemos desconstruir preconceitos de dentro da escola?

Para dar início ao debate, num primeiro momento, busco um melhor entendimento sobre o termo "preconceito" por meio do diálogo entre Hans-Georg Gadamer e Immanuel Kant. A escolha desses autores se justifica por ser possível construir através deles uma reflexão sobre o preconceito sob dois pontos de vista; a) a partir de Kant, que, no contexto do Esclarecimento, defendeu a luta da razão contra os preconceitos trazidos pela tradição e; b) a partir de Gadamer, que propôs um resgate do termo por tê-lo visto como parte indissociável da compreensão humana. Depois de construída essa reflexão sobre o 
"preconceito", volto a pôr em análise as manifestações de preconceito que ocorrem dentro da escola com o objetivo de ampliar a compreensão sobre esse fenômeno que deixa registros tão ruins na memória de pessoas que pertencem a grupos minoritários.

Num segundo momento, proponho-me a analisar se é possível desconstruir preconceitos de dentro da escola. A discussão, no entanto, não se dará exatamente no campo da análise de práticas educativas específicas nem sobre um ou outro modelo de escola possível. A intenção é avaliar que elementos, dentro das práticas, são fundamentais para a promoção dessa mudança. Posso adiantar aqui que o presente ensaio, inspirado na hermenêutica gadameriana, focará em dois elementos: a autoridade, encarnada na figura do professor e na própria instituição escolar, e o diálogo.

Como relata Vera Candau (2010), é crescente a quantidade de estudos e pesquisas que se propõem a identificar, descrever e denunciar situações de discriminação e de exclusão dentro da escola. Com isso, essas diferenças que eram em grande parte silenciadas ou invisibilizadas, hoje são percebidas como algo que precisa ser mais bem compreendido. Candau também relata que, em pesquisas recentes realizadas pelo $\mathrm{Gecec}^{1}$, grupo que coordena, percebeu que dentro da escola essa consciência também é cada vez mais forte entre educadores, como mostra a fala de um professor: "“as diferenças estão bombando na escola"”. (2010, p.2)

Como já esclareci anteriormente, não é intenção deste ensaio abordar especificamente de nenhum grupo identitário, mas ater-se às questões que envolvem o preconceito em si, uma vez que esse é um tema que geralmente permeia as discussões sobre minorias dentro e fora do contexto escolar. É importante também já de início esclarecer que hoje, mesmo com a democratização do ensino no nosso país, essas minorias ainda podem ser consideradas minorias no sentido trazido por Andrade:

Não obstante, não podemos esquecer que "maioria" e "minoria" são conceitos muito relativos e ambíguos. Não os uso aqui no sentido quantitativo, numérico. Mas com relação ao poder, às vantagens e ao reconhecimento que determinados grupos têm na sociedade. (ANDRADE, 2009, p.23)

O termo "minoria" será então usado neste ensaio com o mesmo sentido, para se referir àqueles que carregam em si uma marca identitária que, por uma conjuntura histórica, foi discriminada negativamente e que lutam para que os preconceitos e as representações sobre essa marca se desconstruam e sejam ressignificados positivamente. Dessa forma, parto da compreensão de que a discriminação pautada em preconceitos construídos sobre essa marca identitária é o que coloca mulheres, negros, deficientes, homossexuais em desvantagem de poder nas relações que estabelecem.

\footnotetext{
${ }^{1}$ Grupo de Estudos sobre o Cotidiano, Educação e Cultura(s) 


\section{2) Preconceito}

Kant, no contexto do Esclarecimento, foi um dos grandes defensores da luta entre a razão e os preconceitos trazidos pela tradição. Era seu objetivo mostrar que todo conhecimento que nos fora fornecido de antemão deveria ser submetido ao julgamento da razão. Para Kant (1974), essa era a maneira de nos livrarmos de possíveis erros e enganos que eram passados de geração em geração e colocar a humanidade no caminho do progresso. Ele vislumbrava um momento em que os homens pudessem autonomamente distinguir o certo do errado.

Essa crença no progresso da humanidade era motivada pela possível existência de uma razão universal. Inspirado pelas descobertas científicas da época, principalmente as de Newton, Kant dedicou-se à construção de um sofisticado sistema filosófico a respeito das faculdades da razão humana, no qual ainda hoje se baseiam em grande medida as noções democráticas que temos de liberdade, autonomia e indivíduo.

Dessa forma, como percebe Gadamer, o Esclarecimento promoveu um preconceito contra os preconceitos, e revestiu a palavra "preconceito" de um sentido eminentemente negativo, sentido este que a palavra, ela mesma, não comporta. Assim como acontece com a palavra da língua portuguesa, e igualmente como acontece, por exemplo, na palavra inglesa prejudice, a palavra alemã, Vorurteil, utilizada pelo autor, carrega em seu significado literal o sentido de juízo prévio, julgamento prévio ou preconceito. Esse julgamento prévio não é nem positivo e nem negativo a princípio. Aliás, embora não seja comum pensarmos dessa forma, é bem possível que tenhamos um juízo prévio ou preconceitos positivos sobre algo. Exemplo disso é que, mesmo que uma pessoa nunca tenha estado pessoalmente nas Ilhas Caribenhas, pelos relatos que essa pessoa já ouviu, ela pode já esperar que vá ser um bom passeio para as próximas férias, o que já denota aqui que em grande parte pautamos nossas escolhas por esses preconceitos, muito embora, é claro, eles possam nos trazer frustrações. Algo pode não ser tão bom quanto se esperava por esse ou aquele motivo. O mesmo pode se dar de forma contrária. Quando alguém nos adverte que algo é ruim, estamos dispostos a criar maus preconceitos. Esses prejulgamentos vão se construindo de uma ou de outra maneira sem que, na maior parte do tempo, nos demos conta disso.

Evidentemente, o Esclarecimento estava preocupado com questões mais complexas. A ideia era combater preconceitos herdados que se solidificavam ao longo da história nos campos dos conhecimentos mais formais, conhecimentos estes que eram decisivos para a humanidade e para o modo como os homens se conduziriam socialmente. Kant, como um dos principais defensores desse ideal, pregava que todos aqueles modos de conhecer que não fossem passíveis de uma explicação racional, aos moldes do saber científico moderno, deveriam sofrer descrédito. Assim, todos os homens deveriam pautar suas ações em conhecimentos racionalmente fundamentados, pois todos seriam dotados de uma razão que, em última análise, os permitia diferenciar o certo e o errado. O que se torna mais emblemático em seus escritos sobre esse aspecto é o imperativo categórico, presente em um de seus mais célebres escritos Crítica da Razão Prática, publicado pela primeira vez em 1788. No imperativo, que ele denominou como sendo "A lei fundamental 
da razão prática pura", Kant dizia: "Age de tal modo que a máxima de tua vontade possa sempre valer ao mesmo tempo como princípio de uma legislação universal." (2003, p.103).

Para Gadamer (1999), o problema do pensamento racional moderno estaria justamente em entender o preconceito, ou as antecipações que a nossa inserção no mundo nos permite fazer, como uma limitação para o conhecimento. Ao colocar em descrédito todo juízo de caráter histórico que era fornecido pela tradição, o Esclarecimento não percebeu que todo o

nosso conhecimento tem raízes na prática das relações pré-científicas que mantemos com as coisas e as pessoas. Isso significa que nosso saber mantém vínculos estreitos com o mundo prático, antes de desenvolver qualquer tematização. Estamos, assim, desde já inseridos num mundo que constitui o horizonte em que se realizam nossos processos compreensivos. (HERMANN, 2002, p. 20)

Sendo assim, o próprio horizonte de conhecimentos é o que nos permite conhecer, não existe um ponto arquimediano para fora disso. Para considerar que a razão pudesse colocar diante de si todo o conhecimento, Kant precisou reconhecê-la como sendo transcendental e não histórica ou, em outras palavras, algo que está para além do que é mundano.

Podemos então considerar que os preconceitos que são historicamente fornecidos pela nossa tradição são necessários não só para a nossa ação como também para a construção do nosso conhecimento sobre o mundo. Eles, como nos fala Hermann (2002), constituem o horizonte de sentidos que compartilhamos uns com os outros e é o que permite nos guiar pelo mundo, estabelecer relações com as pessoas, as coisas, as nossas práticas e instituições e até mesmo tematizar o nosso próprio conhecimento e ação.

Dessa forma, não só não é possível eliminar todos os nossos preconceitos, como também não é desejável fazê-lo. Contudo, reconhecendo sua historicidade, podemos sim estabelecer uma postura crítica com relação a eles, ainda que de modo limitado, pois, como nos alerta Gadamer, "os preconceitos de um indivíduo são muito mais do que seus juízos, são a realidade histórica de seu ser”. Assim, a tomada de consciência sobre nossos preconceitos representam "uma centelha na corrente cerrada da vida histórica" (1999, p.426).

Essa análise, um tanto desanimadora, pode gerar muitas discordâncias, mas em certa medida nos leva a compreender por que, a despeito de toda a nossa vontade mais sincera e a despeito de toda a luta contrária, é tão difícil desconstruirmos e ressignificarmos pensamentos que foram historicamente sedimentados. A história, contudo, nos mostra que esses preconceitos se alteram e isso acontece em grande parte por conta daqueles que, embora tenham percebido que o trabalho era difícil, não se desanimam e conduziram grandes transformações na sociedade. 


\section{3) Memória}

Retomando o exemplo inicial dos relatos sobre a escola, coloco agora as seguintes perguntas: Como se formam memórias? Por que as experiências ruins são tão difíceis de serem esquecidas? Por que a escola é algo que está na memória de alguns adultos como sendo um lugar tão difícil, principalmente para aqueles que pertencem a uma minoria identitária? Com a intenção de acrescentar algo às ponderações sobre o tema, atenho-me aqui ao que Gadamer traz a partir da hermenêutica.

Gadamer (1999) nos alerta que para compreender a essência da memória, devemos nos desvencilhar da ideia de que ela não é mais do que uma capacidade genérica. Para Gadamer, memória é parte da história do homem e de sua formação. Por isso reter, esquecer e voltar a lembrar pertencem à constituição histórica do homem. Nas palavras de Gadamer (1999, p.56), "a memória não é memória como tal e para tudo. Para algumas coisas temos memória, para outras não, e algumas coisas queremos guardar na memória, outras banir". Vemos, então, que o sentido de memória é mais amplo do que aquele conhecido como um armazenamento de informações, experiências ou conhecimentos, pois, a memória também é parte da constante formação humana. Pertencem à memória não somente aquilo que lembramos, mas também aquilo que esquecemos (GADAMER, 1999, p.56).

Essa possibilidade de renovação é o que permite que nos transformemos, que mudemos nossa percepção sobre o mundo e sobre fatos já ocorridos e que sejamos capazes de resignificar preconceitos que trazemos. Isso também se dá no âmbito coletivo, no sentido de resignificarmos a história de um povo, de um gênero ou dos grupos que têm necessidades especiais diversas. Evidentemente, mais uma vez, essa transformação não se dá somente sob a ação da vontade individual, ela é parte de um movimento de mudança dos preconceitos que compartilhamos coletivamente.

É comum a ideia de que é importante conhecermos a nossa história para não cairmos novamente nos mesmos erros. No entanto, o sentido da história se constitui de acordo com as interpretações que nos são legadas, portanto, a própria história é um campo de disputas. Sendo assim, a maneira como interpretamos a história pode ser modificada. Percebemos esse caráter dinâmico da história quando novas interpretações possibilitam o surgimento de novos fatos que não correspondem à "história oficial".

Quando compreendemos a história como um tempo vivo ou "entrecruzado", como definiu Walter Benjamin (2008), vemos que o tempo comporta passado, presente e futuro em um mesmo agora. Neste sentido, o agora não é mais um ponto em uma ordem linear, mas o lugar em que a construção da história está sempre em questão Dessa forma, como adverte o autor, "nem mesmo os nossos mortos estão salvos". Temos que a cada dia salvar sua memória, dada a contínua possibilidade de resignificar a história que contamos sobre eles. Nas palavras do autor:

o dom de despertar no passado as centelhas da esperança é privilégio exclusivo do historiador convencido de que também os mortos não estarão em segurança se o inimigo vencer. E esse inimigo não tem cessado de vencer. (BENJAMIN, 2008, p. 224) 
Esse é, para o autor, o encontro marcado entre os antepassados com as gerações futuras. Esse compromisso com o passado requer que escovemos a história a contrapelo, resgatemos aquilo que não foi contado para que um dia, talvez, possamos dizer que quem construiu os grandes palácios e monumentos foram aqueles que carregaram suas pedras, e não reis e imperadores.

Voltando aos relatos sobre as más experiências na escola, podemos, então, chegar à conclusão de que há ainda o que se fazer a respeito dessas memórias. É possível alterar seu significado, uma vez que o contexto histórico, em que os preconceitos surgem, podem ainda ganhar novas interpretações. Essa, contudo não é uma tarefa fácil ou possível de se realizar simplesmente a partir de nossa vontade. O movimento de reinterpretação é uma tarefa constante, que comporta a tensão do campo de disputa que é a própria história.

\title{
4) Preconceito e escola
}

\begin{abstract}
A escola pode dar acesso a importantes instrumentos de redistribuição de poder nesta sociedade, tais como o conhecimento sistematizado sobre direitos, o domínio sobre a língua nacional, o conhecimento sobre a própria história ou o controle sobre argumentos científicos. Por outro lado, como instrumento de sociabilidade, a escola poderia ajudar também a construir o prestígio social dos grupos socialmente marginalizados, valorizando as diferentes identidades, reconhecendo valores e riquezas em todos os grupos culturais, desconstruindo preconceitos, favorecendo a coexistência pacífica entre todos e reforçando uma convivência mais dialógica entre os diferentes. O lamentável é que a escola pode também ser um importante mecanismo de exclusão, dando a alguns o acesso aos mecanismos de poder (direito, língua, história, ciência etc.) e negligenciando a outros. A escola pode socializar com ênfase no respeito à diferença, mas pode também uniformizar (uniforme, provas únicas, currículo único, a mesma maneira de ensinar para todos etc.). (ANDRADE, 2009, p.29)
\end{abstract}

Inicio esta segunda parte do ensaio com esta longa citação por ver nela uma síntese de muitos daqueles impasses envolvidos na abordagem da diversidade na escola. É preciso avaliar a escola como uma instituição dotada de legitimidade suficiente para propor-se à realização dessa tarefa. Ao mesmo tempo, não se negligencia o fato de a educação escolar também estar carregada de dispositivos que impedem uma posição favorável à diversidade. Em muitas ocasiões, esses dispositivos tendem a reforçar preconceitos e naturalizar relações de dominação em vez de permitir uma problematização obstinada. É preciso, portanto submetê-los ao debate, insistir no diálogo crítico e buscar alternativas.

O objetivo não deve se reduzir a uma busca de meios para que grupos minoritários alcancem mais postos de trabalho e melhores posições sociais. Nesse sentido, a escola também não deve servir apenas a isso. Referindo-se aos movimentos que lutam pelos direitos das minorias, Andrade nos fala a 
outra frente de luta do multiculturalismo é o reconhecimento social, pois as discriminações que sofrem os diferentes não se tratam apenas de privações de melhores condições socioeconômicas. É preciso desconstruir também todo um sistema de produção de sentido, de significados sobre esses grupos. Aqui a luta é no espaço simbólico. (ANDRADE, 2009, p.27)

Sendo assim, buscaremos aqui pensar em que se baseia o poder transformador da escola. Como pode ela desconstruir preconceitos? Não discutiremos aqui questões relativas às práticas pedagógicas em si, mas sim buscaremos colocar em evidência alguns dos elementos que se colocam como fundamentais para a promoção dessa mudança. A escolha desses elementos se deu pelo seguinte caminho: em geral, ao vislumbrar uma transformação nas relações, não há quem não considere a importância do diálogo, a importância de dar voz ao outro, de abrir espaço para que a diferença, o não hegemônico se manifeste. Diante disso, temos o diálogo como um elemento importante. Contudo, o que confere à escola o poder de propor o diálogo? De colocá-lo onde antes ele não existia? Não podemos ignorar que mesmo quando a ideia é promover um ambiente em que todos tenham o mesmo direito à voz, há ainda aquilo que podemos chamar de "violência da iniciativa" (GADAMER, 2004, p.311). Quando o diálogo não se dá de forma amistosa e espontânea, propor o diálogo requer que a iniciativa parta de alguém. Assim, é possível questionar: o que confere à escola o poder ou o direito de tomar tal iniciativa? Dessa maneira, o segundo elemento, que, ao que parece, precede o primeiro, é a autoridade.

Do mesmo modo como "preconceito", a palavra "autoridade" também pode nos provocar certo incômodo, pois nos remete à sua face mais cruel: o autoritarismo. Contudo, ela continua sendo importante para designar algo que fenomenologicamente se dá. É nesse sentido, que aqui, mais uma vez inspirada na hermenêutica gadameriana, recoloco esse tema.

\section{5) Autoridade}

Cuche (2002, p.186), inspirado em suas leituras de Bourdieu, afirma que "somente os que dispõem de autoridade legítima, ou seja, de autoridade conferida pelo poder podem impor suas próprias definições de si mesmo e dos outros". Evidentemente, aqui o autor se refere a certo tipo de autoridade: àquela conferida a grupos hegemônicos, que historicamente ocupam uma posição de poder. Contudo, na nossa sociedade o termo autoridade também tem o sentido de domínio sobre determinado campo de conhecimento. Só pode ser reconhecido como médico, músico, policial, juiz, professor aquele que provou ter o conhecimento suficiente para tal. Assim, essa pessoa tem conferido a ela a autoridade sobre determinado campo de conhecimento. O professor, por conta disso, é alguém que tem o poder conferido a ele, tem a autoridade para se encarregar da formação de seus alunos. Essa formação é entendida num sentido amplo, uma vez que também a instituição escolar tem a autoridade, socialmente reconhecida, de formar pessoas para a

sociedade.

Como vimos no início deste ensaio, Gadamer reconheceu os preconceitos como sendo inerentes à compreensão humana, opondo-se ao ideal de razão concebido na modernidade. 
Isso fez também com que ele se visse diante da necessidade de repensar a questão da autoridade. O Esclarecimento, ao promover o preconceito contra o preconceito, acabou por descaracterizar o próprio conceito de autoridade, por ser a autoridade uma das principais fontes de preconceito (GADAMER, 1999). Entretanto, é justamente na elucidação do caráter da autoridade que é possível encontrar as bases que sustentam a figura do educador e da instituição escolar no pensamento hermenêutico de Gadamer.

O Esclarecimento promoveu o embate entre a razão e toda e qualquer autoridade ao considerar que somente a primeira levava à liberdade, enquanto a segunda levava à obediência cega. Gadamer, no entanto, contesta que a autoridade tenha essa essência ao afirmar que a autoridade só pode existir onde há reconhecimento e conhecimento. Assim, o que legitima a existência do mestre como uma autoridade é justamente o reconhecimento de que ele está "acima de nós em juízo e perspectiva e que, por consequência, seu juízo precede, ou seja, tem primazia em relação ao nosso próprio" (GADAMER, 1999, p. 419). Esse reconhecimento é condição para que a autoridade exista. Para Gadamer: "autoridade não tem nada a ver com obediência cega de comando. Na realidade, autoridade não tem nada a ver com obediência, mas com conhecimento" (GADAMER, 1999: 419). Com isso, podemos entender que aquele que se torna educador não o pode fazer através de uma concessão, mas sim pela conquista de um reconhecimento que o legitima nessa posição. Da mesma forma, a escola só tem autoridade quando é reconhecida como tal.

Muito embora a tradição já confira à escola e ao professor esse poder em grande medida, o reconhecimento desses como autoridades precisa ser reafirmado a cada vez. Aqui, arrisco-me a dizer que a questão levantada por Gadamer sobre a legitimação da autoridade pode explicar até certo ponto por que alguns professores parecem ter mais poder do que outros sobre aquilo que se propõem a fazer e por que algumas escolas também parecem ter mais autoridade sem que precisem recorrer ao autoritarismo. Uma vez que é através do reconhecimento que a autoridade e o poder se legitimam, uma escola ou um professor que não são legitimados pelo grupo ao qual pertencem têm poucas chances de obter sucesso em suas ações. Mas essa é apenas uma questão especulativa. Voltando à análise sobre a escola hoje, vemos que no campo da educação é comum a ideia de que a escola se encontra em crise. Essa crise, que parece se confundir com a própria crise da subjetividade moderna, tem revelado muito daquilo que tradicionalmente a escola vinha reafirmando e que hoje parece já não mais dar conta da realidade. Em outras palavras, a escola que antes era "monocultural", apoiando-se numa pretensa universalidade do conhecimento que se propunha a difundir, hoje se vê diante da necessidade de se colocar em questão e se reinventar. Como mostra Candau:

Estamos desafiados a reconhecer e valorizar as diferenças culturais, os diversos saberes e práticas, e a afirmar sua relação com o direito à educação de todos/as. Reconstruir o que consideramos "comum" a todos e todas, garantindo que nele os diferentes sujeitos socioculturais se reconheçam, garantindo assim que a igualdade se explicite nas diferenças que são assumidas como comum referência, rompendo assim com o caráter monocultural da cultura escolar. (CANDAU, 2010, p.10) 
Sendo assim, a escola pode ser sim um lugar privilegiado para a promoção do diálogo, mas só conseguirá desconstruir e transformar preconceitos quando ela mesma compreender que precisa avaliar em que pressupostos se fundamentam suas bases. Caso contrário, continuará reproduzindo desigualdades e negando as diferenças.

\section{6) Diálogo}

O diálogo é um tema bastante caro à filosofia hermenêutica e tem sido elemento de discussão nos mais variados campos de conhecimento. Ao que parece, quanto mais se assume a insuficiência de se pensar uma razão universal que, aos moldes do Esclarecimento kantiano, pretendia tudo conhecer autonomamente, mais se reconhece a necessidade do diálogo para a construção do conhecimento. Isso significa dizer que aquele conhecimento que tinha um caráter universal e que deu base para as ciências modernas, hoje pode ser compreendido como um tipo de saber específico que na verdade foi universalizado graças a uma relação de poder que colocou a cultura ocidental europeia acima das outras.

Retomando a temática do diálogo, como vimos na primeira parte do trabalho, Gadamer compreendeu que os preconceitos são mais do que juízos prévios, são a própria base da compreensão humana. Eles, no entanto, podem, até certo ponto, ser tematizados e revistos e é nesse ponto que o diálogo aparece com mais força na filosofia gadameriana. Gadamer compreendeu que o processo educativo do homem é algo que nunca se conclui totalmente e entendeu esse "educar como um educar-se" (2000), uma relação em que aquele que se educa o faz em contato com o outro através do diálogo. É justamente no diálogo que o sujeito torna explícitas suas opiniões prévias e, na tentativa de se fazer entender e também de entender o outro, formula e reformula essas opiniões e, assim, se educa com o outro. Esse é, portanto, um processo cujos resultados não podemos antever. Como explica Hermann:

Uma perspectiva hermenêutica na educação retoma seu caráter dialógico com toda a radicalidade. (...) O diálogo não é um procedimento metodológico, mas se constitui na força do próprio educar - que é educar-se - no sentido de uma constate confrontação do sujeito consigo mesmo, com suas opiniões e crenças, pela condição interrogativa na qual vivemos. (HERMANN, 2002: 94)

Gadamer defendeu que o que permite o diálogo é o fato de todos nós estarmos, desde sempre, inscritos em um mundo, que nos dá o horizonte de sentidos do qual compartilhamos. Esse horizonte de sentidos é justamente aquilo que Gadamer chamou de preconceitos. Como foi discutido anteriormente, os preconceitos são algo que necessariamente compartilhamos e são eles o que nos permitem o diálogo. Por mais que eu nunca tenha estado na Índia, eu compartilho de um horizonte de sentidos fornecido pelo meu mundo, ou seja, pelas informações que obtive aqui e ali sobre esse país, que poderá servir de base para que alguém que já tenha estado lá e saiba mais sobre a cultura local possa vir a dialogar comigo. Quando entramos em diálogo, nossos horizontes de 
sentido se fundem e os preconceitos que tenho relacionados à Índia são colocados em debate. Esse, para Gadamer, é o verdadeiro diálogo, que só ocorre quando algo é de fato discutido. Eu me abro para o que o outro diz por reconhecer nele uma fonte legítima de conhecimento e coloco meus preconceitos em jogo para serem transformados.

O diálogo, no entanto, nem sempre vai resultar em entendimento sobre algo ou em um consenso. Quando nós já de antemão não estamos dispostos a colocarmos sob avaliação os nossos preconceitos, por um ou outro motivo, a pessoa com quem dialogamos está privada "formalmente de sua pretensão de dizer a verdade" (GADAMER, 1999, p.454).

O diálogo em Gadamer comporta uma série de nuances que merecem ser analisadas com muita atenção, no entanto, os principais elementos sobre essa temática já foram esboçados aqui e já nos dão base para colocar as questões: há na escola espaço para o diálogo? A estrutura da escola é favorável para o diálogo? Evidentemente, existem escolas que já estão atentas a essa necessidade. Essas escolas abrem espaço para que o diálogo ocorra de forma genuína, dando voz àquele que aprende, reconhecendo que este é o verdadeiro protagonista do processo de educação. Mas também, mais do que isso, tais escolas permite que aquele que aprende coloque seus preconceitos em jogo e avalie sua legitimidade através do diálogo com o grupo e com os professores. O professor, como alguém que, a princípio, tem autoridade para tal, deve estar atento para "cometer a violência da iniciativa" (GIEGEL apud GADAMER, 2004, p.311), sempre que for necessário.

Gadamer, contudo, reconhece que não há diálogo possível com um número muito grande de pessoas reunidas: "nas situações de ensino, quando esta ultrapassa a intimidade de um pequeno círculo, reside uma dificuldade intransponível para o diálogo" (2004, p.248). Por conta disso, reconhecemos que a própria estrutura escolar que comumente encontramos hoje demonstra que o que acontece, na maioria das vezes, é na verdade um monólogo protagonizado pelo professor. Com isso, por ser o diálogo também um exercício, diante das raras situações que se apresentam favoráveis, ele acaba ficando prejudicado, o que é perfeitamente compreensível. Ora, se o exercício da narrativa é constantemente cerceado, a capacidade para o diálogo evidentemente se torna cada vez menor.

\section{7) Conclusão}

Foi com a intenção de colocar em debate elementos que estão na base das discussões sobre as discriminações, que esse ensaio se propôs a trazer para o diálogo algumas questões que estão presentes em Gadamer, um dos principais autores da tradição hermenêutica. Nesse sentido, discutimos aqui principalmente os temas do preconceito, da memória, da autoridade e do diálogo.

Mesmo tendo hoje mais alunos pertencentes a grupos minoritários na escola, isso não significa uma melhora direta na problemática dos preconceitos. Hoje, caso a escola não esteja atenta à diversidade, não assumindo uma postura consciente, está fadada a continuar sendo um local privilegiado para a discriminação negativa e para a formação de 
memórias ruins nos indivíduos. Isso ocorre porque, se a escola não se coloca em questão e não reconhece quais preconceitos estão nas suas próprias bases, ela não terá sua autoridade legitimada para colocar nenhum outro preconceito em diálogo.

A afirmação de Gadamer de que "a educação é educar-se", nos leva a ver a experiência educativa como algo que não se pode impor ao outro e que a pretensão de objetificar o sujeito e a sua aprendizagem não encontra nenhum amparo no modo próprio de ser da educação. O diálogo, por sua força vinculante, é o que nos permite a todo o momento elaborar e reelaborar nossos preconceitos, no esforço que fazemos para compreender e de nos tornarmos compreensíveis ao outro. Evidentemente, naquele modelo onde o espaço para o diálogo é restringido, as possibilidades para a transformação de preconceitos também serão menores.

\section{Referências bibliográficas}

ANDRADE, Marcelo (org.) A diferença que desafia a escola: a prática pedagógica e a perspectiva intercultural, in: ANDRADE, M. A Diferença que desafia a escola, Rio de Janeiro: Quartet/Faperj, 2009, p. 13-47

BENJAMIN, Walter. Obras Escolhidas - Magia e Técnica, Arte e Política. São Paulo: Brasiliense, 2008.

CANDAU, Vera Maria. As diferenças fazem diferenças? Cotidiano Escolar, Interculturalidade e Educação em Direotos Humanos. In: XV ENDIPE - Encontro Nacional de didática e Prática de Ensino, 2010, Belo Horizonte. Coleção Didática e Prática de Ensino. Belo Horizonte: Autêntica, 2010. p. 756-771..

CUCHE, Denys. A noção de cultura nas ciências sociais. $2^{\mathrm{a}}$ ed. Tradução Viviane Ribeiro. Buaru, Edusc. 2002.

GADAMER, Hans-Georg. Verdade e Método II. Tradução de Enio Paulo Giachini. 2. ed. Petrópolis: Vozes, 2004.

La Educación es Educarse. Tradução de Francesc Pereña Blasi. Barcelona: Paidós, 2000. 1999.

Verdade e Método I. Tradução de Flávio Paulo Meurer. 3. ed. Petrópolis: Vozes,

GOMES, Nilma Lino. Educação, Identidade negra e formação de professores/as: um olhar sobre o corpo negro e o cabelo crespo. Educação e Pesquisa, v.29, n.1, p.167182, jan./jun. 2003.

HERMANN, Nadja. Hermenêutica e Educação. Rio de Janeiro: DP\&A, 2002. 
KANT, Immanuel. Crítica da razão prática. Edição bilíngüe. Tradução: Valerio ohden São Paulo: Martins Fontes, 2003.

Resposta à Pergunta: Que é "Esclarecimento"? In: KANT, Immanuel. Textos Seletos, Petrópolis: Vozes, 1974.

WALSH, Catherine. Interculturalidad y (de)colonialidad: Perspectivas críticas y políticas. XII Congreso da Association pour la Recherche Interculturelle. Florianópolis: UFSC, Brasil, 2009. 